\title{
Pharmacogenetics-based warfarin dose prediction algorithm for patients with heart valve replacement in Southeast China
}

\author{
M.Q. Lin' ${ }^{1 *}$, J. Zhang1*, H.F. Qiu ${ }^{2}$, X.B. Xie ${ }^{2}$ and H.T. Song ${ }^{1}$ \\ ${ }^{1}$ Department of Pharmacy, Fuzhou General Hospital, Fuzhou, Fujian, China \\ ${ }^{2}$ Department of Cardiac Surgery, Fujian Medical University Union Hospital, \\ Fuzhou, Fujian, China \\ *These authors contributed equally to this study. \\ Corresponding author: H.T. Song \\ E-mail:mqzjcn@126.com
}

Genet. Mol. Res. 16 (3): gmr16038881

Received June 14, 2016

Accepted July 3, 2017

Published July 28, 2017

DOI http://dx.doi.org/10.4238/gmr16038881

Copyright (C) 2017 The Authors. This is an open-access article distributed under the terms of the Creative Commons Attribution ShareAlike (CC BY-SA) 4.0 License.

\begin{abstract}
This study was designed to analyze the influence of polymorphisms in CYP2C9, VKORC1, CYP4F2, GGCX, and EPHX1 genes on the optimal warfarin dosage in patients who have undergone artificial heart valve replacement and establish an algorithm for use by physicians in Southeast China to predict each patient's optimal steadystate warfarin dose. One-hundred and ninety-six patients scheduled for heart valve replacement in Southeast China were enrolled in this study. Five genotypes, CYP2C9, VKORC1, CYP4F2, GGCX and EPHX1, were detected using time-of-flight mass spectrometry. Correlations of clinical and genetic factors with optimal steady-state dose of warfarin were analyzed. There were significant correlations between the genotypes of CY2C9, VKORC1, CYP4F2 and the warfarin dosage $(\mathrm{P}=0.000,0.000$ and 0.015$)$. Multiple stepwise regression analysis was performed to obtain the following algorithm: [Dose $(\mathrm{mg} /$ day $)=$ $\operatorname{EXP}(0.540+0.544 \times V K O R C 1-0.392 \times C Y P 2 C 9+0.342 \times C Y P 4 F 2$ $+0.474 \times$ BSA $-0.005 \times$ Age) $]$. This algorithm could predict $49.2 \%$ of
\end{abstract}

Genetics and Molecular Research 16 (3): gmr16038881 
the observed differences in optimal warfarin dosage among the enrolled patients. A retrospective validation study comparing this algorithm with the published algorithms used in patient populations of other races revealed that the obtained algorithm had the best accuracy (The smallest MRE: $21.11 \pm 19.08 \mathrm{mg} /$ day) and applicability (the largest RE proportion of patients in ideal rang: $58.3 \%$ ). This study 1 ) defined the relative contributions of age, body surface area, and polymorphisms in CYP2C9, VKORC1, and CYP4F2 to the optimal steady-state dosage of warfarin; 2) established a dose prediction algorithm for populations in this region that takes into account the clinical, pharmacological and genetic polymorphism data; and 3) clarified the advantages of this algorithm over the established prediction equations. Our algorithm can assist clinicians in Southeast China in prescribing appropriate anticoagulation therapy.

Key words: Warfarin; Heart valve replacement surgery; Genetic pharmacology; CYP2C9; VKORC1

\section{INTRODUCTION}

A mechanical heart valve is treated as a foreign substance by the human body, which increases the risk of thrombus formation that can block the valve leaf and impair valve function. In severe cases, this can cause heart failure or sudden death. If a clot breaks free from the primary site of formation at the mechanical valve, it can cause an embolism in functional organs or tissues, resulting in hemiplegia, aphasia, pulmonary embolism, lower limb arterial embolism, and other problems. Anticoagulation therapy is thus very important after heart valve replacement. Warfarin is currently the only oral anticoagulant administered after replacement of a mechanical heart valve. Normalization of anticoagulation therapy with this drug is an important step to improve the quality of life of the patients. Large differences in effective dose between individuals, a narrow therapeutic window (an inadequate dose can easily result in thrombosis, whereas an overdose easily leads to hemorrhage), interactions with foods and other drugs, the requirement for frequent monitoring of each patient's international normalized ratio (INR), and poor patient compliance complicate the clinical application of warfarin. Certain genetic polymorphisms have been shown to affect the required therapeutic dose of warfarin. These include polymorphisms in the genes VKORC1, CYP2C9 (Alrashid et al., 2016), CYP4F2, GGCX, and EPHX1 (Liu et al., 2015; Sun et al., 2015, 2016; Wakamiya et al., 2016).

The Food and Drug Administration (FDA) has updated warfarin labeling twice, prompting physicians to consider the presence of genetic polymorphisms in cytochrome $\mathrm{P} 450$ protein 2C9 (CYP2C9) and vitamin K epoxide reductase complex subunit 1 (VKORC1) when selecting a patient's initial dose of warfarin therapy. A recent, multi-center, large-sample study showed that genotype-guided warfarin dose selection was superior to dose selection guided by clinical data (Pirmohamed et al., 2013). In particular, genotype-guided dose selection increased INR-in-target-range time, which strongly supports the value of gene-guided warfarin dose prediction. However, these genetic polymorphisms can only explain the differences in effective dose in $30-60 \%$ of the individuals receiving warfarin (Sconce et al., 2005; Gage et

Genetics and Molecular Research 16 (3): gmr16038881 
al., 2008; Wen et al., 2008; Huang et al., 2009; Klein et al., 2009; Ohno et al., 2009). It is also necessary to consider the patient's body surface area (BSA), liver and kidney functions, other medications taken, and other factors in selecting the appropriate dose. This requires a dose prediction method that considers both the genetic and clinical factors to guide the clinical use of warfarin. In China, no representative warfarin dose algorithm has yet been adopted for clinical application. This study establishes an equation for optimizing warfarin dosage in patients in Southeast China, and compares it with other published algorithms. The objective of this study was to identify the most suitable method for providing guidance to physicians in establishing warfarin dosage for patients who have undergone surgical replacement of a mechanical heart valve in Southeast China.

\section{MATERIAL AND METHODS}

\section{Study subjects}

One-hundred and ninety-six patients who underwent mechanical heart valve replacement surgery in a third-level grade-A hospital in Fuzhou between February 2013 and October 2013 and met the inclusion criteria for this study were selected. This study was conducted in accordance with the declaration of Helsinki. This study was approved by the Ethics Committee of Fujian Medical University. Written informed consents were obtained from all participants.

Inclusion criteria: 1) patient aged $\geq 18$ years at the time of enrollment; 2) patient receiving warfarin therapy and dose optimization for the first time as a result of their valve replacement surgery; and 3) patient agreeing to participate in this study and sign the informed consent form.

Exclusion criteria: 1) continuous abnormal liver and kidney functions; 2) congestive heart failure; 3) thyroid dysfunction; 4) coagulation disorders; 5) cancer; and 6) pregnant or currently breastfeeding patients.

\section{Data collection}

1) Demographics: The data on gender, age, height, and weight of each patient were collected from the hospital information system. BSA was calculated as follows: BSA $\left(\mathrm{m}^{2}\right)=$ $0.61 \times$ height $(\mathrm{m})+0.0128 \times$ body weight $(\mathrm{kg})-0.1529$. 2) Clinical indicators: hypertension, diabetes, smoking, and drinking. 3) Gene polymorphisms: CYP2C9*3, VKORC1-1639A/G, cytochrome P4504F2 (CYP4F2) rs2108622 (T > C), GGCX rs12714145 (T > C), and EPHX1 rs4653436 (A > G). 4) Steady-state dose of warfarin: the warfarin dose at which the INR values remain within the target range over two consecutive measurements $\geq 7$ days apart, with little fluctuation in the previous tests except for extenuating circumstances.

\section{Gene detection method}

Venous blood (2-3 $\mathrm{mL})$ was drawn from each patient, placed in an ethylenediaminetetraacetic acid (EDTA)-containing tube, and stored at $4^{\circ} \mathrm{C}$. Whole blood DNA was extracted using a whole blood genomic DNA rapid extraction kit (centrifugal column), (Beijing BioTeke Corporation, Beijing, China.) A time-of-flight mass spectrometry platform (Sequenom) was used for genotyping (BioMiao Biological Technology (Beijing) Co., Ltd., Beijing, China).

Genetics and Molecular Research 16 (3): gmr16038881 


\section{Anticoagulation programs}

Anticoagulant standards: Expected INR values for aortic valve replacement patients ranged from 1.5 to 2.0 , whereas those for mitral or mitral and aortic bi-valve replacement patients were 1.7 to 2.3 , and those for tricuspid valve replacement patients were 2.0 2.5. For all patients, the values were expected to fall between 1.5 and 2.5 .

Dose adjustment: If the INR value decreased below 1.5 for four consecutive days, the dose would be increased. However, if it showed an upward trend at the predicted optimum dosage, appropriate reduction should be performed. If it was higher than 2.5, the dose would be reduced. Increase and decrease in dose were performed in increments of $0.625 \mathrm{mg} /$ day or $0.75 \mathrm{mg} /$ day (1/4 tablet).

\section{Monitoring of INR}

Each patient's INR was measured every other day in the hospital and after the patient was discharged. When a patient's INR was within the target range over two consecutive measurements, the frequency of monitoring was extended to twice per week. When a patient's INR was again within the target range over two consecutive measurements, the frequency of monitoring was extended to once per week. By the same criterion, the frequency of monitoring was reduced to once per two weeks, then once per month, and once every two months. The detection interval did not exceed two months. If the INR fluctuated, the frequency of monitoring was increased.

\section{Model selection and validation}

We screened the published literature for foreign and domestic warfarin dose algorithms used to predict the optimal steady-state dose of warfarin for individual patients. The accuracy and applicability of each model were then evaluated, respectively, and compared with those of the model developed in this study.

Evaluation of accuracy: The mean relative error (MRE) was considered the main outcome indicator, and was defined as the mean value of the relative error $(\mathrm{RE}) . \mathrm{RE}=\mid$ Predicted dose - actual dosage $/$ actual dose $\times 100 \%$.

Comparison of clinical applicability: The proportion of patients with RE within $\pm 20 \%$ (ideal RE range) was compared between the groups (Finkelman et al., 2011; Shin and Cao, 2011; Liu et al., 2012).

\section{Statistical analysis}

SPSS17.0 statistical software was used for the related statistical processing.

\section{RESULTS}

\section{Basic patient information}

Seventy-two of the enrolled patients were men, and 124 patients were women. The age of the enrolled patients ranged from 18 to 72 years, with an average age of $48.87 \pm 11.65$ 
years. The height of the patients ranged from 1.38 to $1.85 \mathrm{~m}$, with an average height of $1.61 \pm$ $0.08 \mathrm{~m}$. Body weight ranged from 33 to $92 \mathrm{~kg}$, with an average body weight of $56.60 \pm 10.54$ $\mathrm{kg}$. Fourteen of the 196 patients exhibited CYP2C9 mutation, all of whom harbored *1/*3type mutation. Twenty-eight patients exhibited a mutation in VKORCl $-1639 \mathrm{C}>\mathrm{T}$, of whom 2 patients were homozygous and 26 patients were heterozygous. Ninety-three patients exhibited a mutation in CYP4F2 rs2108622, of whom 15 patients were homozygous and 78 patients were heterozygous. Mutations in GGCX rs12714145 and EPHX1 rs4653436 were observed in 119 and 80 patients, respectively. Thirty-four patients had their aortic valve replaced, and 154 had their mitral valve or both mitral and aortic valves replaced. Eight patients had their tricuspid valve replaced. Genotyping results and valve types are shown in Table 1. The stablestate dose of warfarin was $3.18 \pm 1.19 \mathrm{mg} /$ day.

\begin{tabular}{|c|c|c|c|}
\hline Characteristics & Value $[\mathrm{N}(\%)]$ & Characteristics & Value [N (\%)] \\
\hline CYP2C 9 & & $G G C X r_{s} 12714145$ & \\
\hline${ }^{*} 1 / *_{1}$ & $182(92.86 \%)$ & $\mathrm{CC}$ & $74(38.34 \%)$ \\
\hline$* 1 / * 3$ & $14(7.14 \%)$ & CT & $96(49.74 \%)$ \\
\hline VKORCI $-1639 \mathrm{C}>\mathrm{T}$ & & TT & $23(11.92 \%)$ \\
\hline TT & $168(85.71 \%)$ & EPHXI rs 4653436 & \\
\hline $\mathrm{CT}$ & $26(13.27 \%)$ & $\mathrm{GG}$ & $114(58.76 \%)$ \\
\hline $\mathrm{CC}$ & $2(1.02 \%)$ & GA & $73(37.63 \%)$ \\
\hline CYP4F2 rs2108622* & & AA & $7(3.61 \%)$ \\
\hline $\mathrm{CC}$ & $102(52.31 \%)$ & Indications & \\
\hline $\mathrm{TC}$ & $78(40.00 \%)$ & AVR & $34(17.35 \%)$ \\
\hline \multirow[t]{2}{*}{ TT } & $15(7.69 \%)$ & MVR + DVR & $154(78.57 \%)$ \\
\hline & & TVR & $8(4.08 \%)$ \\
\hline
\end{tabular}

*The genotype of CYP4F2 was not detected in one patient.

\section{Influence of $C Y P 2 C 9, V K O R C 1$, and $C Y P 4 F 2$ polymorphisms on steady-state dose}

As shown in Table 2, the average steady-state dose in the patients with $C Y P 2 C 9^{*} 1 / * 3$ was $1.04 \mathrm{mg} /$ day less than that in the patients with the $* 1 / * 1$ genotype $(\mathrm{P}<0.05)$. No patients with $C Y P 2 C 9 * 3 / * 3$ genotype were reported. The average steady-state dose in the patients with VKORC1-1639 TT wild homozygous genotype was $1.72 \mathrm{mg} /$ day less than that in CT genotype patients $(\mathrm{P}<0.05)$, and $4.34 \mathrm{mg} /$ day less than that in $\mathrm{CC}$ genotype patients $(\mathrm{P}<0.05)$. The homozygous $C Y P 4 F 2$ gene polymorphism had a significant effect on the steady-state warfarin dose $(\mathrm{P}<0.05)$; however, there was no significant difference in steady-state dose between patients with wild-type CYP4F2 and those with mutant heterozygous type CYP4F2 (P > 0.05).

Table 2. Correlation between $C Y P 2 C 9, V K O R C 1$, and $C Y P 4 F 2$ polymorphisms and the steady-state warfarin dose.

\begin{tabular}{|c|c|c|c|c|c|c|}
\hline Factors & Group & Number (\%) & Stable dose $(\mathrm{mg} / \mathrm{d})$ & Minimum $(\mathrm{mg} / \mathrm{d})$ & Maximum $(\mathrm{mg} / \mathrm{d})$ & P value \\
\hline \multirow[t]{2}{*}{ CYP2C9 } & $* 1 / * 1$ & $182(92.86 \%)$ & $3.26 \pm 1.19$ & 1.13 & 8.25 & 0.000 \\
\hline & $* 1 / * 3$ & $14(7.14 \%)$ & $2.22 \pm 0.79$ & 1.20 & 3.75 & \\
\hline \multirow{3}{*}{ VKORC1 } & TT & $168(85.71 \%)$ & $2.91 \pm 0.88$ & 1.13 & 6.0 & 0.000 \\
\hline & CT & $26(13.27 \%)$ & $4.63 \pm 1.32$ & 3.0 & 8.25 & \\
\hline & $\mathrm{CC}$ & $2(1.02 \%)$ & $7.25 \pm 1.41$ & 6.25 & 8.25 & \\
\hline \multirow[t]{3}{*}{$C Y P 4 F 2$} & $\mathrm{CC}$ & $102(52.31 \%)$ & $3.02 \pm 1.10$ & 1.13 & 8.25 & \multirow[t]{2}{*}{0.015} \\
\hline & TC & $78(40.00 \%)$ & $3.22 \pm 1.21$ & 1.25 & 8.25 & \\
\hline & TT & $15(7.69 \%)$ & $3.95 \pm 1.38$ & 2.50 & 7.00 & \\
\hline
\end{tabular}

Genetics and Molecular Research 16 (3): gmr16038881 


\section{Steady-state dose of warfarin in different genotypes}

To compare patients with simultaneous mutations in two genotypes and those with single gene mutation, different genotypes were grouped, as shown in Table 3. As shown in Tables 2 and 3, the highest average steady-state dose was reported in the patients harboring VKORCl CC type $(7.25 \pm 1.41 \mathrm{mg} /$ day $)$, followed by those with $\mathrm{F}+\mathrm{V}$ type $(5.38 \pm 1.52 \mathrm{mg} /$ day). Both doses were significantly higher than that reported in the patients harboring the wild type $(\mathrm{P}<0.05)$. On the contrary, the dose of the $\mathrm{F}+\mathrm{C}$ type group was significantly lower than that of the patients in group $\mathrm{A}(\mathrm{P}<0.05)$. However, the doses used of the patients in groups $\mathrm{C}$ $+\mathrm{V}$ and $\mathrm{A}$ were not significantly different $(\mathrm{P}>0.05)$. Figure 1 compares the average steadystate doses among all groups.

Table 3. Mean steady-state dose in patients of different genotypes.

\begin{tabular}{l|l|c|c}
\hline Group & Genotype & Number & Steady-state dose $(\mathrm{means} \pm \mathrm{SD})(\mathrm{mg} / \mathrm{d})$ \\
\hline $\mathrm{A}$ & Wild type & 90 & $2.95 \pm 0.91$ \\
\hline $\mathrm{F}_{1}$ & CYP4F2 CT & 63 & $3.01 \pm 0.80$ \\
\hline $\mathrm{F}_{2}$ & CYP4F2 TT & 13 & $3.83 \pm 1.12$ \\
\hline $\mathrm{C}$ & CYP2C9 $1 / * 3$ & 6 & $1.81 \pm 0.40$ \\
\hline $\mathrm{V}$ & VKORC1 TC & 13 & $4.62 \pm 1.37$ \\
\hline $\mathrm{F}+\mathrm{V}$ & CYP4F2 CT/TT VKORC1 TC/CC & 12 & $5.38 \pm 1.52$ \\
\hline $\mathrm{F}+\mathrm{C}$ & CYP4F2 CT/TT CYP2C9 $* 1 / * 3$ & 6 & $1.95 \pm 0.33$ \\
\hline $\mathrm{C}+\mathrm{V}$ & CYP2C9 $* 1 / * 3$ VKORC1 TC & 3 & $3.50 \pm 0.43$ \\
\hline
\end{tabular}

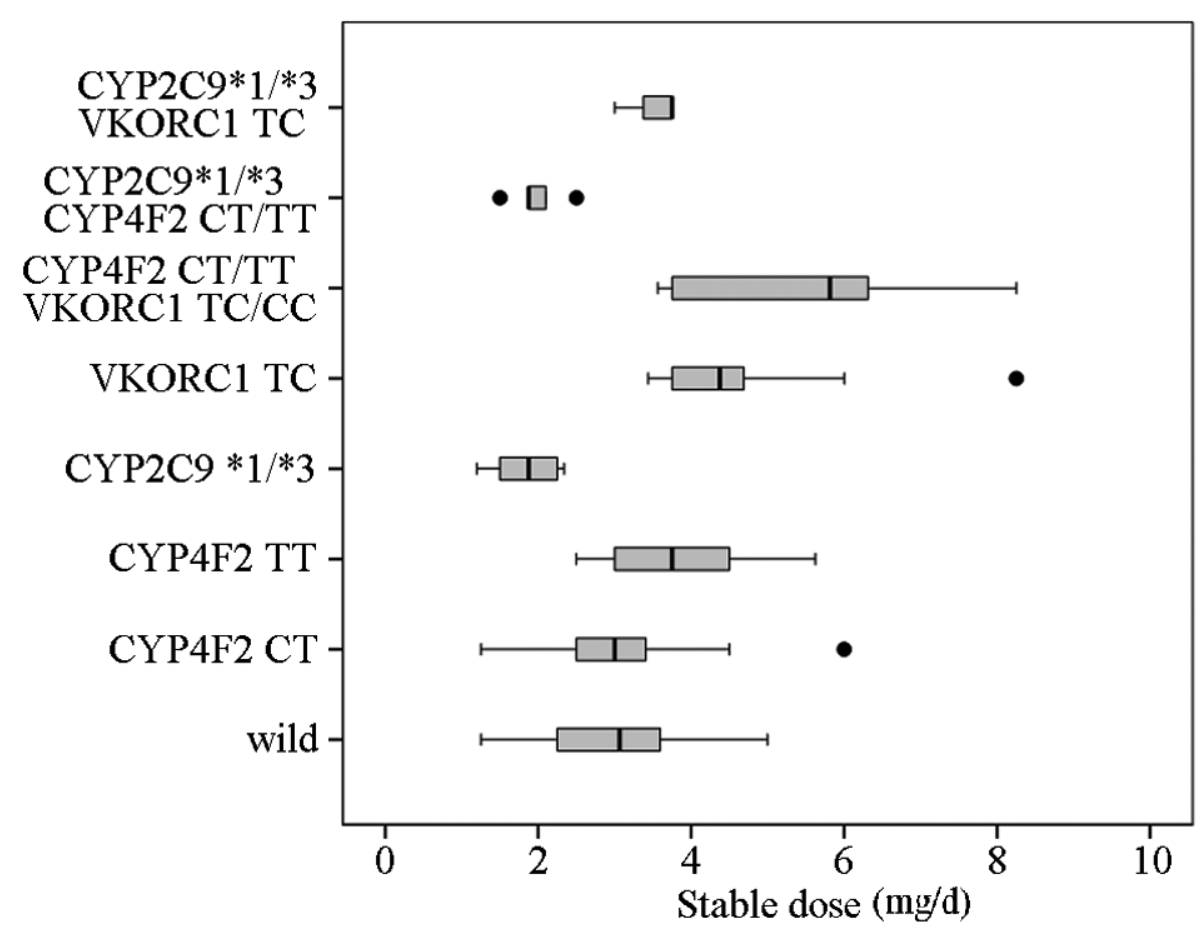

Figure 1. Box plot for the distribution of warfarin dose in patients with different CYP2C9, VKORC1 and CYP4F2 polymorphs.

Genetics and Molecular Research 16 (3): gmr16038881 


\section{Establishing a prediction equation by multiple linear regression analysis}

The K-S (Kolmogorov-Smirnov) normal distribution test showed that the steadystate doses were not normally distributed $(\mathrm{P}<0.05)$. When the data were log-transformed, the results were normally distributed $(\mathrm{P}>0.05)$; therefore, the following analysis used the logarithmic steady dose [ln (Dose)] as the dependent variable, as shown in Figure 2.
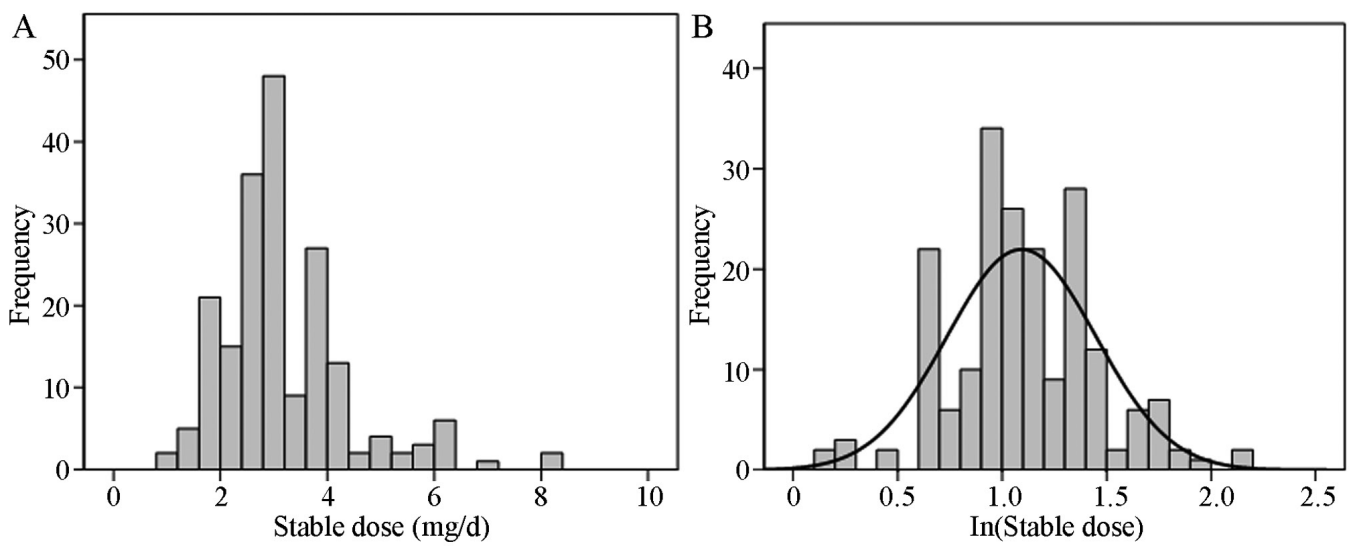

Figure 2. Histogram of warfarin steady-state dose frequency distribution.

Polymorphisms in CYP2C9, VKORC1, CYP4F2, GGCX, and EPHX1, age, and BSA were selected as the independent variables for the regression analysis, whereas $\ln$ (Dose) was the dependent variable. The following equation was obtained by the multiple linear regression analysis:

Dose $(\mathrm{mg} /$ day $)=\operatorname{EXP}(0.540+0.544 \times V K O R C 1-0.392 \times C Y P 2 C 9+0.342 \times$ CYP4F2 $+0.474 \times$ BSA - $0.005 \times$ Age $)$.

Assignment: BSA, m²; Age, year; CYP2C9, *1/*1 $\rightarrow 0, * 1 / * 3 \rightarrow 1$; VKORC1, TT $\rightarrow$ $0, \mathrm{TC} \rightarrow 1, \mathrm{CC} \rightarrow 2 ; \mathrm{CYP} 4 F 2, \mathrm{CC} / \mathrm{CT} \rightarrow 0, \mathrm{TT} \rightarrow 1$.

\section{Inclusion of published model algorithms}

This study included 11 published dose prediction algorithms: the dose formulas of the USA and European countries: Sconce, Wells, Zambon; the Asian dose formulas: Zhu, Huang, Wen, Ohno, Miao, Wei; the mixed-race dose formulas: Gage and IWPC. Formulas are shown in Table 4.

\section{Evaluation of accuracy}

The comparison between the MRE values of the predicted doses and those of the actual steady-state doses is shown in Table 5. The present algorithm showed better predictive accuracy in the populations included in this study. The doses predicted by Wen, Wei, Zhu, and Huang algorithms were also accurate, whereas those predicted by Wells, Miao, and Sconce algorithms were poor.

Genetics and Molecular Research 16 (3): gmr16038881 
Table 4. Algorithms selected for validation analysis.

\begin{tabular}{|c|c|c|c|c|c|c|}
\hline Author & \begin{tabular}{|l|l|l|l} 
Population \\
\end{tabular} & Indications & Derivation/Validation (n) & Algorithm & $\mathrm{R}^{2}$ & \\
\hline Sconce & $100 \%$ Caucasian & $\mathrm{AF}, \mathrm{DVT} / \mathrm{PE}$ & 297 & $\begin{array}{l}\text { Dose(mg/d) }=0.628-0.0135(\mathrm{Age})-0.24\left(\mathrm{CYP}^{*}\right)-0.370\left(\mathrm{CYP}^{*} 3\right)-0.241 \\
\text { (VKORC1 C1173T) }+0.0162(\mathrm{Height})\end{array}$ & $54.2 \%$ & Sconce et al., 2005 \\
\hline Zhu & $100 \%$ Caucasian & $\mathrm{AF}$ & 65 & 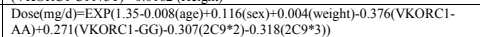 & $61.0 \%$ & Zhu et al., 2007 \\
\hline Wells & 94\% Caucasian & $\begin{array}{l}\text { DVT, PE, AF, MHVR, } \\
\text { Other }\end{array}$ & 249 & 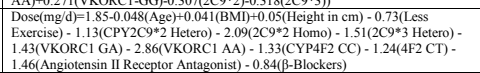 & $58 \%$ & Wells et al., 2010 \\
\hline Zambon & $100 \%$ Caucasian & AF, DVT, Others & 371 & 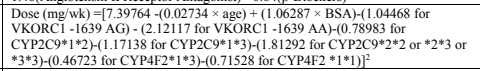 & $65.4 \%$ & Zambon et al., 201 \\
\hline Gage & $\begin{array}{l}3 \% \text { Caucasian } / \\
15 \% \text { African-American } \\
2 \% \text { Other }\end{array}$ & AF, DVT/PE & $1015 / 292$ & 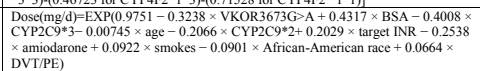 & $53 \%$ & Gage et al., 2008 \\
\hline IWPC & $\begin{array}{l}56 \% \text { Caucasian } / 30 \% \text { Asian } / \\
10 \% \text { African-American } / 5 \% \text { Other }\end{array}$ & AF, DVT/PE & $4043 / 1009$ & 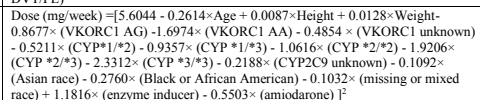 & $47 \%$ & Klein et al., 2009 \\
\hline Wen & $100 \%$ Chinese & $\begin{array}{l}\text { AF, Stroke, DVT, } \\
\text { HVR }\end{array}$ & 108 & $\begin{array}{l}\text { Dosec(mg/d) }=-0.443-0.018 \times \mathrm{Age}+1.4 \times \mathrm{BSA}-0.269 \times \mathrm{HT}+0.798 \times \text { Predict } \\
\text { Dose }\end{array}$ & $62.0 \%$ & Wen et al., 2008 \\
\hline Miao & $100 \%$ Chinese & MHVR, AF, DVT/PE & 178 & $\begin{array}{l}\text { Dose(mg/d) }=6.222-0.011 \times \mathrm{Age}+0.017 \times \text { Weight }-0.775 \times \text { CYP2C9-3.397 } \times \\
\text { (VKORC1GA) }-4.803 \times(\text { VKORC1 AA) }\end{array}$ & $62.8 \%$ & Miao et al., 2007 \\
\hline Ohno & $100 \%$ Japanese & AF, DVT/PE, Other & 125 & 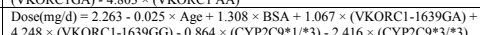 & $54.8 \%$ & Ohno et al., 2009 \\
\hline Huang & $100 \%$ Chinese & MHVR, AF, DVT & $266 / 156$ & 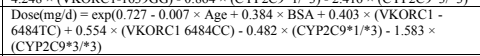 & $54.1 \%$ & Huang et al., 2009 \\
\hline Wei & $100 \%$ Chinese & $\mathrm{AF}$ & $260 / 65$ & 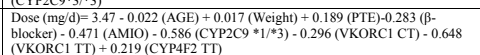 & $43.4 \%$ & Wei et al., 2012 \\
\hline
\end{tabular}

$\mathrm{AF}=$ atrial fibrillation; $\mathrm{DVT}=$ deep vein thrombosis; $\mathrm{PE}=$ pulmonary embolism; $\mathrm{MHVR}=$ machine heart valve replacement; HVR $=$ heart valve replacement.

Table 5. Mean relative error in predicted dose and actual steady-state dose of each algorithm and proportion of patients with relative error within $\pm 20 \%$.

\begin{tabular}{l|c|c|c|c}
\hline \multirow{2}{*}{ Algorithm } & Mean relative error (\%) & \multicolumn{3}{|c}{ Proportion of patients whose relative error are within $\pm 20 \%$} \\
\cline { 2 - 5 } & Means \pm SD & Under & Ideal & Over \\
\hline Sconce & $40.59 \pm 17.00$ & $83.9 \%$ & $5.1 \%$ & $7.0 \%$ \\
\hline Zhu & $23.63 \pm 17.85$ & $42.2 \%$ & $44.8 \%$ & $4.8 \%$ \\
\hline Wells & $34.03 \pm 33.00$ & $10.4 \%$ & $43.2 \%$ & $51.0 \%$ \\
\hline Zambon & $33.06 \pm 31.20$ & $5.7 \%$ & $50.0 \%$ & $39.1 \%$ \\
\hline Gage & $26.58 \pm 26.11$ & $10.9 \%$ & $51.6 \%$ & $37.0 \%$ \\
\hline IWPC & $27.11 \pm 28.05$ & $11.5 \%$ & $54.2 \%$ & $19.8 \%$ \\
\hline Wen & $21.81 \pm 19.80$ & $26.0 \%$ & $22.9 \%$ & $1.6 \%$ \\
\hline Miao & $35.18 \pm 15.75$ & $75.5 \%$ & $56.8 \%$ & $29.7 \%$ \\
\hline Ohno & $24.04 \pm 23.66$ & $13.5 \%$ & $52.1 \%$ & $19.3 \%$ \\
\hline Huang & $23.65 \pm 21.51$ & $28.6 \%$ & $51.0 \%$ & \\
\hline Wei & $23.51 \pm 19.81$ & $32.3 \%$ & $58.3 \%$ & $16.7 \%$ \\
\hline Present & $21.11 \pm 19.08$ & $17.2 \%$ & & $24.5 \%$ \\
\hline
\end{tabular}

\section{Evaluation of clinical applicability}

To further evaluate the clinical applicability of each algorithm, the proportion of patients with RE within $\pm 20 \%$ (ideal RE range) was compared between the groups. The results are shown in Table 5.

The present algorithm exhibited the largest proportion of patients with INR values within the desired range (58.3\%), followed by Ohno (56.8\%), Wen (54.2\%), and Huang (52.1\%). Sconce algorithm (83.9\%) was the most likely to underestimate the dose, followed by Miao (75.5\%).

\section{DISCUSSION}

\section{Influence of clinical factors on steady-state dose of warfarin}

Personalized medicine is becoming a medical reality, wherein important genotype- 
phenotype relationships are being unraveled. The availability of pharmacogenomic data is a key element in individualized health care (Liboredo and Pena, 2014). Zhu et al. (2007) took into consideration the influence of gender in a warfarin administration program. They have shown that the dose of warfarin required for male patients is lower than that required for female patients. However, most other studies have not suggested that the gender has a significant influence on the steady-state dose of warfarin. Results of this study also showed that the gender had no significant effect on the steady-state warfarin dose.

The influence of age was much more significant. With increasing age, the sensitivity of patients to warfarin increases (Saleh, 2016). It was reported that every additional 10 years of age would reduce the steady-state dose of warfarin by $8 \%$ (Gage et al., 2004). This might be because the liver and kidney functions in the elderly are weaker than those in younger and middle-aged people; thus, the activity of the drug-metabolizing enzymes and metabolism of warfarin decrease with age, resulting in a reduction in the required warfarin dose (Shepherd et al., 1977). The results of this study also showed that the required warfarin dosage decreased with increasing age.

This study did not include patients aged $<18$ years. One study that examined 118 juvenile patients, aged 0-18 years, with heart disease (Moreau et al., 2012) showed that the height, target INR values, and VKORC1 and CYP2C9 polymorphisms were the major factors that determine the maintenance dose of warfarin, with 48.1, 4.4, and 18.2, and 2.0\% contribution, respectively. Another study on 0- to 18-year-old juvenile patients (Biss et al., 2012) also showed that the BSA, height, weight, age, and polymorphisms of VKORC1 and CYP2C9 genes significantly affected the warfarin dose, among which the BSA and height were the most accurate predictors of warfarin dose. The maintenance dose of warfarin in pediatric patients is mainly affected by height, followed by the gene polymorphisms. In 0to 18-year-old patients, differences in height and BSA are more obvious. The liver size is positively correlated with the height and/or BSA. With increase in height or BSA, the liver becomes larger, leading to increased clearance rates of warfarin (Takahashi et al., 2000).

Height, body weight, and BSA are often included in the dosing regimens as minor factors (Klein et al., 2009). The BSA is calculated from the height and weight. As the height, weight, and BSA increase, the steady-state dose of warfarin also increases. Not all studies confirmed the effect of BSA on warfarin dose. Some studies (Wen et al., 2008; Ohno et al., 2009; Zambon et al., 2011) suggested that a higher BSA correlated with a higher steady-state dose of warfarin. Other studies (Sconce et al., 2005; Miao et al., 2007) suggested that the BSA had no effect on the steady-state dose of warfarin. The regression model used in this study incorporated the BSA; however, the results of this study showed no significant effects of height, weight, and BSA on the steady-state dose of warfarin $(\mathrm{P}>0.05)$. This might be because the differences in height, weight, and BSA in this study were not large, and these relatively small differences did not correlate with a measurable difference in dosage within the sample size used in this study.

The disease, smoking, and drinking status of patients might affect the steadystate dose of warfarin. Wen et al. (2008) incorporated the effects of hypertension into the prediction formula; however, the relevance analysis indicated that hypertension did not have a statistically significant impact on the steady-state dose although the predicted dose in patients with hypertension was $0.269 \mathrm{mg} /$ day less than that in non-hypertensive patients. The results of this study showed that the average warfarin dose in patients with hypertension was 0.21 $\mathrm{mg}$ /day lower than that in non-hypertensive patients, which is consistent with the findings of

Genetics and Molecular Research 16 (3): gmr16038881 
Wen et al. (2008). The effects of hypertension and diabetes mellitus on steady-state warfarin dose were not clear, which might be related to the effect of the combination therapy with antihypertensive drugs (including diuretic antihypertensive drugs) and hypoglycemic agents. In this study, drug interactions were not considered as influencing factors. In addition, alcohol has biphasic effects on the liver drug-metabolizing enzymes. High concentrations might inhibit these enzymes, thus increasing warfarin half-life, whereas long-term alcohol intake often induces the enzyme expression, thus reducing warfarin half-life.

\section{Impact of genetic factors on steady-state dose of warfarin}

CYP2C9 is a warfarin-metabolizing enzyme, and $V K O R C$ is a target protein of warfarin action. The influence of $C Y P 2 C 9$ and $V K O R C 1$ polymorphisms on warfarin dose has already been confirmed. CYP2C 9 mutation leads to decreased enzyme activity, consequently, decreasing the clearance rate of warfarin and reducing its required dose. VKORC1 mutation leads to increased enzyme activity, which activates the coagulation factors and accordingly increasing the required warfarin dose. The results of this study showed that the average dose in the patients harboring * $1 / * 3$-type CYP2C 9 was approximately $32.8 \%$ lower than that in the patients harboring $* 1 / * 1$-type CYP2C9, whereas *3/*3-type CYP2C9 was undetected. The mean dose in the patients with $V K O R C 1$ heterozygous mutations was 0.5 -fold greater than that in the patients who were homozygous for the wild-type allele, whereas patients with VKORC1 homozygous mutations required approximately 1.5 -fold higher dose than those with the wildtype allele, which indicated that the homozygous genotypes had greater impact on warfarin dose than the heterozygous ones. Patients with both CYP2C9 and VKORC1 mutations showed no significant difference in their steady-state dose, compared to those with wild-type allele, which might be because the dose-reducing effects of $C Y P 2 C 9$ polymorphism and the doseincreasing effects of VKORC1 mutation were neutralized; therefore, the final dose was not significantly different from that reported for the patients with the wild-type alleles. The FDA recommends that patients with both CYP2C9 and VKORC1 mutations take the same dose as the patients with the wild-type alleles do, which is consistent with the results of this study. Because this study only included three patients with both CYP2C9 and VKORC1 mutations and the sample size was small, this conclusion is yet to be verified.

The influence of CYP4F2 mutations on warfarin dose varies among different ethnic groups (Shendre et al., 2016). Perini et al. (2010) studied a mixed population and reported no significant effect of $C Y P 4 F 2$ polymorphism on warfarin dose, which contradicts with the results of two studies conducted on Chinese populations (Cen et al., 2010; Li et al., 2012). The results of this study showed that $C Y P 4 F 2$ had a significant effect on warfarin dose. $C Y P 4 F 2$ mutations might increase the required dose of warfarin, which is consistent with that reported by Cen et al. (2010) and Li et al. (2012). The heterozygous mutations of CYP4F2 had little influence, whereas the homozygous mutations of $C Y P 4 F 2$ could significantly influence the steady-state warfarin dose.

The steady-state dose of warfarin in patients with both CYP4F2 and VKORC1 mutations was not significantly different from that in patients with only VKORC1 mutation and those with both $C Y P 2 C 9$ and $V K O R C 1$ mutations, indicating that among the patients with VKORC1 mutations, the effects of mutations in other sites were concealed. Meanwhile, VKORC1 mutation conferred an advantage. Singh et al. (2011) has reported that CYP4F2 polymorphism affects warfarin dose, whereas VKORC1 mutation does not.

Genetics and Molecular Research 16 (3): gmr16038881 
No significant difference in warfarin dose was observed between $G G C X$ rs 12714145 $(\mathrm{T}>\mathrm{C})$ and $E P H X 1$ rs4653436 (A $>\mathrm{G})$ genotypes in this study population, which is consistent with that reported by Rieder et al. (2007), Liang et al. (2013), and Issac et al. (2014).

\section{Evaluation of accuracy and clinical applicability}

This study established a warfarin dose prediction model for patients recovering from mechanical heart valve replacement in Southeast China, and compared its accuracy and clinical applicability with those of the domestic and internationally established published models. Low accuracy increases the probability of prescribing a wrong dose. Predictions that result in high dosage would cause bleeding in patients. However, predictions that result in low dosage can put the patients at a high risk of thrombosis. Therefore, the prediction accuracy of the model is very important, particularly for patients with gene mutations. Table 5 shows that the present algorithm had the best prediction accuracy in this study population, whereas the Asian model algorithms, excluding Miao et al.'s (2007) algorithm, were also accurate. The clinical applicability of the model is reflected by the control of INR after using the predicted dose. All algorithms showed a poor ability to predict the correct dose in this study population $(<60 \%)$. The present algorithm had the best prediction capability in this study population, followed by the Asian population models, such as Ohno, Wen, and Huang algorithms, whereas Gage and IWPC algorithms of mixed populations and the algorithm used in Caucasian populations had poor applicability in this study population. Comparison of the models suggested that the race affected the prediction accuracy of the steady-state warfarin dosage. The algorithms belonging to the Asian populations had better accuracy and clinical applicability in Chinese patients. In addition, the sensitivity of the Asians to warfarin was higher than that of the Caucasians. Thus, the required dose of warfarin in the Asians was lower, and this study used low-intensity anticoagulation therapy; therefore, the Caucasian algorithms and mixed-population algorithms, such as Wells, Zambon, Gage, and IWPC algorithms, which are used mainly for white people, might predict a higher dose in this study population. Because warfarin dose was influenced by Vitamin K intake, race and regional dietary differences might lead to individual differences in warfarin dose; therefore, the dose predicted by Wen, Huang, Wei, and Ohno algorithms was relatively closer to the actual dose. However, the prediction capabilities of Wen, Huang, and Ohno algorithms were better than that of Wei algorithm. The subjects of both the present algorithm and Miao et al. (2007)'s algorithm were from the Chinese Han population, and the predicted dose was relatively low. This might be related to the difference in indication of the included subjects and the INR control. Overall, the accuracy and clinical applicability of the present algorithm were superior to those of the other algorithms used for the population in the studied region.

\section{CONCLUSIONS}

This study established the usefulness of a genetic pharmacology-based warfarin dose prediction algorithm for the populations of Southeast China, and proved its superiority in these populations. This study still has some limitations. First, it included only populations limited to Southeast China. Whether the obtained model can be applied in populations of different regions remains to be verified. Second, this study used a retrospective rather than a predictive approach. Whether the predicted dose of each algorithm can guide the patients and the effect was not known. In the future, we look forward to using the model developed in this study for

Genetics and Molecular Research 16 (3): gmr16038881 
prospective validation and clarification of its advantages for establishing an individualized anticoagulation management model for use in clinical practice.

\section{Conflicts of interest}

The authors declare no conflict of interest.

\section{REFERENCES}

Alrashid MH, Al-Serri A, Alshemmari SH, Koshi P, et al. (2016). Association of genetic polymorphisms in the VKORC1 and CYP2C9 genes with warfarin dosage in a group of Kuwaiti individuals. Mol. Diagn. Ther. 20: 183-190. https:// doi.org/10.1007/s40291-016-0190-7

Biss TT, Avery PJ, Brandão LR, Chalmers EA, et al. (2012). VKORC1 and CYP2C9 genotype and patient characteristics explain a large proportion of the variability in warfarin dose requirement among children. Blood 119: 868-873. https://doi.org/10.1182/blood-2011-08-372722

Cen HJ, Zeng WT, Leng XY, Huang M, et al. (2010). CYP4F2 rs2108622: a minor significant genetic factor of warfarin dose in Han Chinese patients with mechanical heart valve replacement. Br. J. Clin. Pharmacol. 70: 234-240. https:// doi.org/10.1111/j.1365-2125.2010.03698.x

Finkelman BS, Gage BF, Johnson JA, Brensinger CM, et al. (2011). Genetic warfarin dosing: tables versus algorithms. $J$. Am. Coll. Cardiol. 57: 612-618. https://doi.org/10.1016/j.jacc.2010.08.643

Gage BF, Eby C, Milligan PE, Banet GA, et al. (2004). Use of pharmacogenetics and clinical factors to predict the maintenance dose of warfarin. Thromb. Haemost. 91: 87-94.

Gage BF, Eby C, Johnson JA, Deych E, et al. (2008). Use of pharmacogenetic and clinical factors to predict the therapeutic dose of warfarin. Clin. Pharmacol. Ther. 84: 326-331. https://doi.org/10.1038/clpt.2008.10

Huang SW, Chen HS, Wang XQ, Huang L, et al. (2009). Validation of VKORC1 and CYP2C9 genotypes on interindividual warfarin maintenance dose: a prospective study in Chinese patients. Pharmacogenet. Genomics 19: 226-234. https:// doi.org/10.1097/FPC.0b013e328326e0c7

Issac MS, El-Nahid MS and Wissa MY (2014). Is there a role for MDR1, EPHXI and protein Z gene variants in modulation of warfarin dosage? a study on a cohort of the Egyptian population. Mol. Diagn. Ther. 18: 73-83. https://doi. org/10.1007/s40291-013-0055-2

Klein TE, Altman RB, Eriksson N, Gage BF, et al.; International Warfarin Pharmacogenetics Consortium (2009). Estimation of the warfarin dose with clinical and pharmacogenetic data. N. Engl. J. Med. 360: 753-764. https://doi. org/10.1056/NEJMoa0809329

Li JH, Ma GG, Zhu SQ, Yan H, et al. (2012). Correlation between single nucleotide polymorphisms in CYP4F2 and warfarin dosing in Chinese valve replacement patients. J. Cardiothorac. Surg. 7: 97. https://doi.org/10.1186/1749-8090-7-97.

Liang Y, Chen Z, Guo G, Dong X, et al. (2013). Association of genetic polymorphisms with warfarin dose requirements in Chinese patients. Genet. Test. Mol. Biomarkers 17: 932-936. https://doi.org/10.1089/gtmb.2013.0303

Liboredo R and Pena SD (2014). Pharmacogenomics: accessing important alleles by imputation from commercial genomewide SNP arrays. Genet. Mol. Res. 13: 5713-5721. https://doi.org/10.4238/2014.July.25.27

Liu HQ, Zhang CP, Zhang CZ, Liu XC, et al. (2015). Influence of two common polymorphisms in the EPHX1 gene on warfarin maintenance dosage: a meta-analysis. BioMed Res. Int. 2015: 564149.

Liu Y, Yang J, Xu Q, Xu B, et al. (2012). Comparative performance of warfarin pharmacogenetic algorithms in Chinese patients. Thromb. Res. 130: 435-440. https://doi.org/10.1016/j.thromres.2012.02.003

Miao L, Yang J, Huang C and Shen Z (2007). Contribution of age, body weight, and CYP2C9 and VKORC1 genotype to the anticoagulant response to warfarin: proposal for a new dosing regimen in Chinese patients. Eur. J. Clin. Pharmacol. 63: 1135-1141. https://doi.org/10.1007/s00228-007-0381-6

Moreau C, Bajolle F, Siguret V, Lasne D, et al. (2012). Vitamin K antagonists in children with heart disease: height and VKORC1 genotype are the main determinants of the warfarin dose requirement. Blood 119: 861-867. https://doi. org/10.1182/blood-2011-07-365502

Ohno M, Yamamoto A, Ono A, Miura G, et al. (2009). Influence of clinical and genetic factors on warfarin dose requirements among Japanese patients. Eur. J. Clin. Pharmacol. 65: 1097-1103. https://doi.org/10.1007/s00228-009-0685-9

Perini JA, Struchiner CJ, Silva-Assunção E and Suarez-Kurtz G (2010). Impact of CYP4F2 rs2108622 on the stable warfarin dose in an admixed patient cohort. Clin. Pharmacol. Ther. 87: 417-420. https://doi.org/10.1038/clpt.2009.307

Genetics and Molecular Research 16 (3): gmr16038881 
Pirmohamed M, Burnside G, Eriksson N, Jorgensen AL, et al.; EU-PACT Group (2013). A randomized trial of genotypeguided dosing of warfarin. N. Engl. J. Med. 369: 2294-2303. https://doi.org/10.1056/NEJMoa1311386

Rieder MJ, Reiner AP and Rettie AE (2007). Gamma-glutamyl carboxylase (GGCX) tagSNPs have limited utility for predicting warfarin maintenance dose. J. Thromb. Haemost. 5: 2227-2234. https://doi.org/10.1111/j.15387836.2007.02744.x

Saleh MI (2016). Clinical predictors associated with warfarin sensitivity. Am. J. Ther. 23: e1690-e1694. https://doi. org/10.1097/MJT.0000000000000248

Sconce EA, Khan TI, Wynne HA, Avery P, et al. (2005). The impact of CYP2C9 and VKORC1 genetic polymorphism and patient characteristics upon warfarin dose requirements: proposal for a new dosing regimen. Blood 106: 2329-2333. https://doi.org/10.1182/blood-2005-03-1108

Shendre A, Brown TM, Liu N, Hill CE, et al. (2016). Race-specific influence of CYP4F2 on dose and risk of hemorrhage among warfarin users. Pharmacotherapy 36: 263-272. https://doi.org/10.1002/phar.1717

Shepherd AM, Hewick DS, Moreland TA and Stevenson IH (1977). Age as a determinant of sensitivity to warfarin. Br. J. Clin. Pharmacol. 4: 315-320. https://doi.org/10.1111/j.1365-2125.1977.tb00719.x

Shin J and Cao D (2011). Comparison of warfarin pharmacogenetic dosing algorithms in a racially diverse large cohort. Pharmacogenomics 12: 125-134. https://doi.org/10.2217/pgs.10.168

Singh O, Sandanaraj E, Subramanian K, Lee LH, et al. (2011). Influence of CYP4F2 rs2108622 (V433M) on warfarin dose requirement in Asian patients. Drug Metab. Pharmacokinet. 26: 130-136. https://doi.org/10.2133/dmpk.DMPK-10-RG-080

Sun X, Yu WY, Ma WL, Huang LH, et al. (2016). Impact of the CYP4F2 gene polymorphisms on the warfarin maintenance dose: A systematic review and meta-analysis. Biomed. Rep. 4: 498-506.

Sun Y, Wu Z, Li S, Qin X, et al. (2015). Impact of gamma-glutamyl carboxylase gene polymorphisms on warfarin dose requirement: a systematic review and meta-analysis. Thromb. Res. 135: 739-747. https://doi.org/10.1016/j. thromres.2015.01.029

Takahashi H, Ishikawa S, Nomoto S, Nishigaki Y, et al. (2000). Developmental changes in pharmacokinetics and pharmacodynamics of warfarin enantiomers in Japanese children. Clin. Pharmacol. Ther. 68: 541-555. https://doi. org $/ 10.1067 / \mathrm{mcp} .2000 .110977$

Wakamiya T, Hokosaki T, Tsujimoto S, Kadota K, et al. (2016). Effect of VKORC1, CYP2C9, CFP4F2, and GGCX gene polymorphisms on warfarin dose in Japanese pediatric patients. Mol. Diagn. Ther. 20: 393-400. https://doi. org $/ 10.1007 / \mathrm{s} 40291-016-0212-5$

Wei M, Ye F, Xie D, Zhu Y, et al. (2012). A new algorithm to predict warfarin dose from polymorphisms of CYP4F2, CYP2C9 and VKORC1 and clinical variables: derivation in Han Chinese patients with non valvular atrial fibrillation. Thromb. Haemost. 107: 1083-1091. https://doi.org/10.1160/TH11-12-0848

Wells PS, Majeed H, Kassem S, Langlois N, et al. (2010). A regression model to predict warfarin dose from clinical variables and polymorphisms in CYP2C9, CYP4F2, and VKORC1: Derivation in a sample with predominantly a history of venous thromboembolism. Thromb. Res. 125: e259-e264. https://doi.org/10.1016/j.thromres.2009.11.020

Wen MS, Lee M, Chen JJ, Chuang HP, et al. (2008). Prospective study of warfarin dosage requirements based on CYP2C 9 and VKORC1 genotypes. Clin. Pharmacol. Ther. 84: 83-89. https://doi.org/10.1038/sj.clpt.6100453

Zambon CF, Pengo V, Padrini R, Basso D, et al. (2011). VKORC1, CYP2C9 and CYP4F2 genetic-based algorithm for warfarin dosing: an Italian retrospective study. Pharmacogenomics 12: 15-25. https://doi.org/10.2217/pgs.10.162

Zhu Y, Shennan M, Reynolds KK, Johnson NA, et al. (2007). Estimation of warfarin maintenance dose based on VKORC1 (-1639 G>A) and CYP2C9 genotypes. Clin. Chem. 53: 1199-1205. https://doi.org/10.1373/clinchem.2006.078139

Genetics and Molecular Research 16 (3): gmr16038881 